\title{
Surgical treatment of bullous lung disease
}

\author{
PD POTGIETER, SR BENATAR, RP HEWITSON, AD FERGUSON \\ From the Respiratory Clinic, Groote Schuur Hospital, and Departments of Medicine, Anaesthetics, and \\ Thoracic Surgery, University of Cape Town Medical School and Groote Schuur Hospital, Cape, \\ South Africa
}

ABSTRACT Clear guidelines for the selection of patients with large pulmonary bullae and severely impaired lung function for surgery remain to be defined. Twenty-one such patients operated on between 1971 and 1977 are reviewed in an attempt to shed some light on this difficult problem. Four of six patients with preoperative hypercapnia survived and were improved by surgery. There was no mortality among the remaining 15 patients of whom 14 were improved symptomatically by surgery (with improvement in $\mathrm{FEV}_{1}$ and vital capacity in 9). Preoperative bronchograms were used to help identify patients suitable for surgery. The presence of bronchiectasis was predictive of postoperative complications. Better results were obtained in those patients in whom plication or bullectomy could be performed than in those requiring lobectomy.

Large pulmonary bullae usually occur in association with chronic obstructive lung disease. With the passage of time and increase in age the bullae may gradually increase in size and the degree of airways obstruction become more severe. ${ }^{1}$ The selection of those patients who would benefit from surgical treatment of such bullae is both difficult and controversial. ${ }^{2} 3$ Surgery can improve patients by allowing compressed lung tissue to re-expand and less commonly by reducing functional residual capacity (and thus reducing work of breathing) or by removal of dead space. The problem in any individual patient is to assess how much the bulla or bullae contribute to his symptoms and to predict whether surgical treatment will improve pulmonary function and favourably influence the longterm course. Large bullae amenable to surgical therapy are allegedly rare. Twenty-three such patients presented in a 16-year period at the Edinburgh Thoracic Surgical Unit ${ }^{4}$ and 85 patients were operated on at a major centre in Boston over a 23-year period. ${ }^{3}$ In the latter series the patients operated on represented $39.8 \%$ of patients presenting with bullous emphysema during the 23-year period.

In the seven year period 1971-77, 21 patients were operated on for bullous emphysema in the Thoracic Surgical Unit at Groote Schuur Hospital, and these cases are presented to illustrate our approach to

Address for reprint requests: Professor SR Benatar, University of Cape Town, Department of Medicine, Medical School, Observatory, 7925 Cape, South Africa. assessment and management, to compare our results with previously reported series, and to emphasise that many patients with marked disability can be gratifyingly improved with surgery.

\section{Methods}

As in previously reported series, patients whom we selected for surgery represented only a proportion of all patients with bullous lung disease seen in medical and thoracic surgical units. We did not consider for surgery any patients who had small bullae or postinfective cysts in extensively damaged lung tissue. Our selection of cases for surgery was based on the premise that if we could identify compression of relatively normal lung tissue by a large bulla then improvement in pulmonary function could be anticipated after surgery.

Our investigations of patients in an endeavour to assess compression, included PA and lateral chest radiographs, bronchograms, ventilation perfusion lung scans, ventilatory function tests, measurement of carbon monoxide gas transfer by the single breath method, and blood gas analysis.

Clinical features of the patients operated on are shown in table 1 . There were 17 males and four females with an average of 41 years (range 15 to 64 years).

Two patients were asthmatic, two had a history of previous pulmonary tuberculosis, and the remainder had chronic bronchitis. Hypercapnia was present preoperatively in six patients (table 2) and the 
Potgieter, Benatar, Hewitson, Ferguson

Table 1 Clinical features and complications

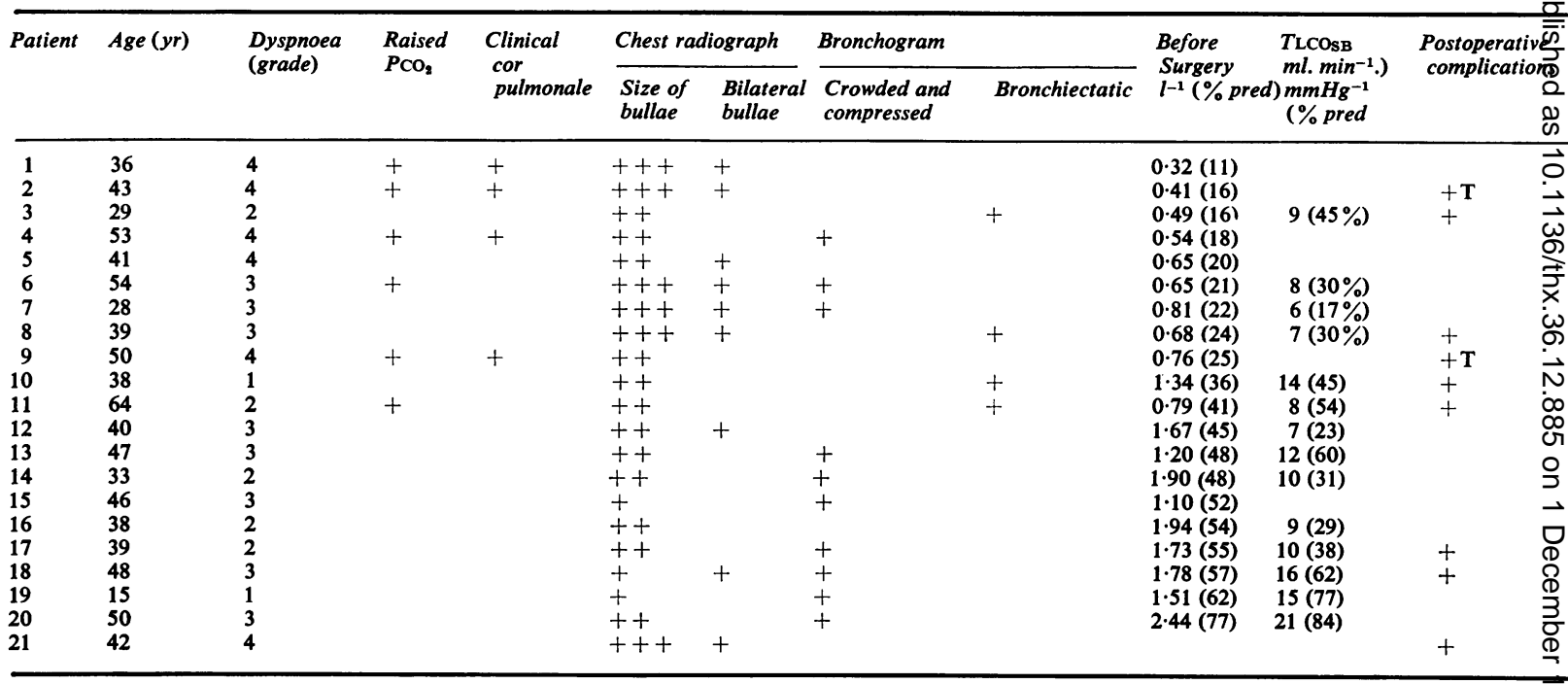

$\begin{array}{rrr}\text { Size of bullae } & < & \text { 1 Hemithorax } \\ +t< & \text { Hemithorax } \\ +t+> & \text { Hemithorax }\end{array}$

$\mathbf{T}=$ deaths

Table 2 Blood gases in subjects with hypercapnia

\begin{tabular}{|c|c|c|c|c|c|c|c|}
\hline \multirow{2}{*}{$\begin{array}{l}\text { Patient } \\
\text { number }\end{array}$} & \multicolumn{3}{|c|}{ Before operation } & \multicolumn{4}{|c|}{ After operation } \\
\hline & $p H$ & $\mathrm{PaO}_{2}$ & $\mathrm{PaCO}_{2}$ & $p H$ & $\mathrm{PaO}_{2}$ & $\mathrm{PaCO}_{2}$ & \\
\hline 1 & $7 \cdot 34$ & $\begin{array}{l}60 \\
(8)\end{array}$ & $\begin{array}{l}54 \\
(7 \cdot 2)\end{array}$ & $7 \cdot 46$ & $\begin{array}{l}63 \\
(8 \cdot 4)\end{array}$ & $\begin{array}{l}38 \\
(5 \cdot 1)\end{array}$ & $\mathrm{mmH}_{\mathrm{kPa}}$ \\
\hline 2 & $7 \cdot 37$ & $\begin{array}{l}45 \\
(6)\end{array}$ & $\begin{array}{l}64 \\
(8 \cdot 5)\end{array}$ & \multicolumn{4}{|c|}{ Died } \\
\hline 4 & $7 \cdot 3$ & $\begin{array}{l}56 \\
(7 \cdot 5)\end{array}$ & $\begin{array}{l}50 \\
(6 \cdot 7)\end{array}$ & $7 \cdot 4$ & $\begin{array}{l}79 \\
(10 \cdot 5)\end{array}$ & $\begin{array}{l}49^{*} \\
(6 \cdot 5)\end{array}$ & $\mathrm{mmH}_{\mathbf{k P a}}$ \\
\hline 6 & $7 \cdot 36$ & $\begin{array}{l}45 \\
(6)\end{array}$ & $\begin{array}{l}56 \\
(7 \cdot 5)\end{array}$ & $7 \cdot 38$ & $\begin{array}{l}65 \\
(8 \cdot 7)\end{array}$ & $\begin{array}{l}51 * \\
(6 \cdot 8)\end{array}$ & $\mathrm{mmHg}_{\mathrm{kPa}}$ \\
\hline 9 & $7 \cdot 39$ & $\begin{array}{l}55 \\
(7 \cdot 3)\end{array}$ & $\begin{array}{l}43 \\
(5 \cdot 7)\end{array}$ & \multicolumn{4}{|c|}{ Died } \\
\hline 11 & $7 \cdot 41$ & $\begin{array}{l}78 \\
(10 \cdot 4)\end{array}$ & $\begin{array}{l}55^{*} \\
(7 \cdot 3)\end{array}$ & $7 \cdot 44$ & $\begin{array}{l}86 \\
(11 \cdot 5)\end{array}$ & $\begin{array}{l}35 \\
(4 \cdot 7)\end{array}$ & $\underset{\mathbf{k P a}}{\mathrm{mmHg}_{\mathbf{g}}}$ \\
\hline
\end{tabular}

${ }^{*} \mathrm{FiO}_{2} \pm 0.24$

diagnosis of cor pulmonale was made clinically in four of these. The size of the bullae was determined from the plain chest radiograph (and the bronchogram) and classified into three categories: those that occupied less than half a hemithorax, those that occupied between half and one hemithorax, and those that were more than one hemithorax in size.

Sixteen of the patients were operated on because of severe dyspnoea and four patients because of a spontaneous pneumothorax in association with a large bulla (patients 5,10,15, and 18). One asthmatic patient with a large bulla was operated on, though her symptoms were probably largely caused by her asthma (patient 19). In this patient the rationale for bullectomy was to improve her pulmonary reserve and reduce the risk of a spontaneous pneumothorax during an asthmatic attack.

\section{Results}

The exact nature of the surgical procedure was determined by the findings at thoracotomy. Fifteen patients had bullectomies or plications, while three required lobectomies (patients $8,10,16$ ) and three needed bullectomy and decortication (patients 3,9 , and 18). Bilateral bullectomy was performed in two patients, in one at the same operation through a median sternotomy (patient 6) and in the other with staged thoracotomies three weeks apart (patient 7). Both these patients had gross compression of lung tissue by the bullae and very poor pulmonary function. The pre and postoperative radiographs of patient 7 are shown in figs 1 and 2 and bronchogram in fig 3.

Five of the six patients with preoperative hypercapnia were ventilated electively postoperatively. All the other patients were managed conservatively with oxygen, physiotherapy, and carefully monitored intravenous analgesia. Postoperative complications occurred in nine patients and complications were more common in patients who had lobectomies or decortication (table 3). All patients with bronchiectasis on the bronchogram or a history of pulmonary 


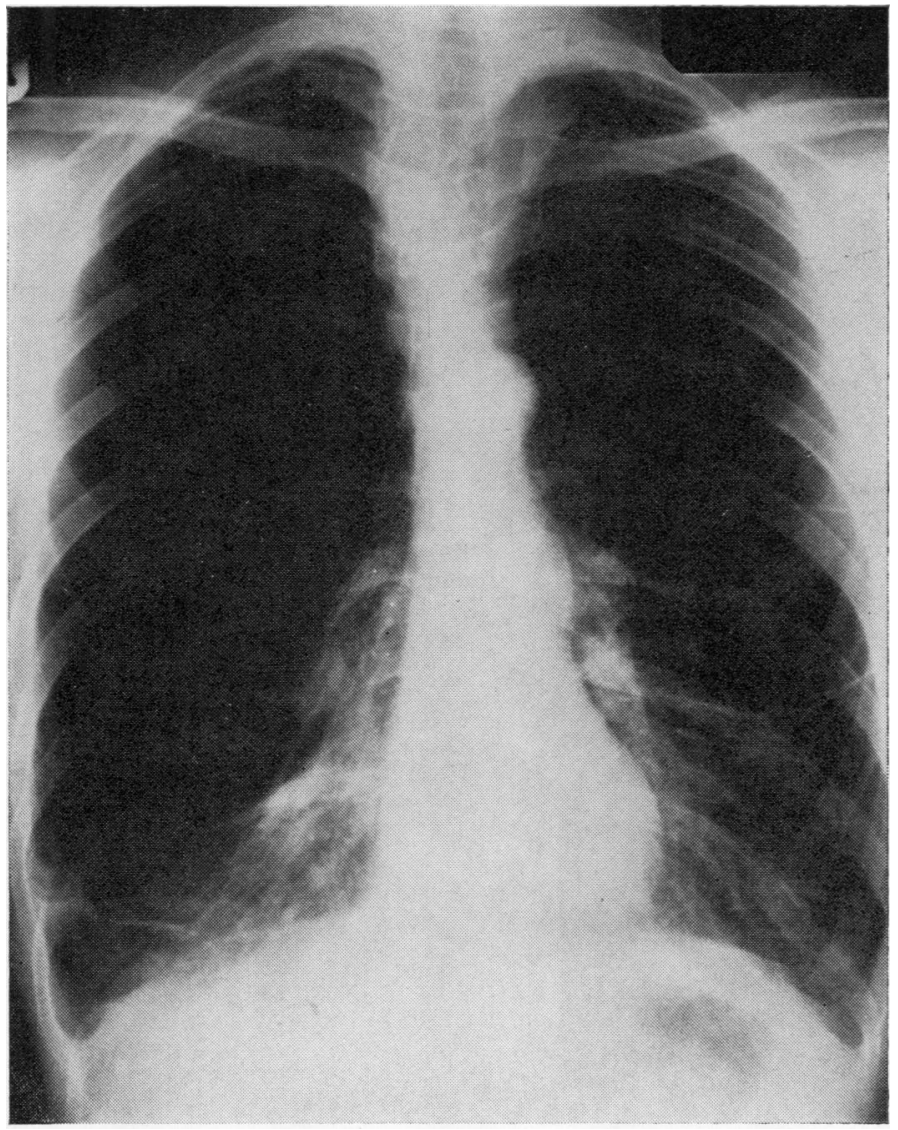

Fig 1 Preoperative $P A$ chest radiograph in patient 7.

tuberculosis had postoperative complications (table 1). In one patient an air leak persisted for four months and in another a residual airspace required tube thoracostomy. Two patients with preoperative hypercapnia and clinical cor pulmonale died (table 2), one immediately after operation because of inadequate ventilation thought to be the result of a contralateral pneumothorax. The other died three weeks after surgery from septicaemia complicating an empyema. One patient needed a thoracoplasty at the time of thoracotomy because the remaining lung tissue failed to fill the pleural space after lobectomy. Postoperative chest radiographs showed that compressed lung re-expanded in all except two patients. The asthmatic patient with only mild symptoms before operation was unchanged afterwards, whereas the remaining 18 patients all showed symptomatic improvement. Associated objective improvement was noted in 12 of 13 patients who had spirometry before and after operation, the only patient not showing such improvement being the asthmatic (table 4). One patient
Table 3 Postoperative complications (nine patients)

\begin{tabular}{llll}
\hline & $\begin{array}{l}\text { Bullectomy } \\
(n=15)\end{array}$ & $\begin{array}{l}\text { Lobectomy } \\
(n=3)\end{array}$ & $\begin{array}{l}\text { Bullectomy and } \\
\text { decortication } \\
(n=3)\end{array}$ \\
\hline $\begin{array}{l}\text { Death } \\
\begin{array}{l}\text { Persisting } \\
\text { pneumothorax }\end{array}\end{array}$ & 1 & & 1 \\
\begin{tabular}{l} 
Empyema \\
\hline
\end{tabular} & 2 & 1 & 3 \\
\hline
\end{tabular}

died from gastrointestinal haemorrhage six months after operation and another required upper lobectomy for carcinoma in the opposite lung. The remaining patients have been followed for three to nine years and in all the improvement in ventilatory function has been sustained.

\section{Discussion}

In patients with bullous lung disease, dyspnoea may result from the pathological effects of the bullae (compression of functioning lung, increased dead space, or hyperinflation with loss of elastic recoil) or 


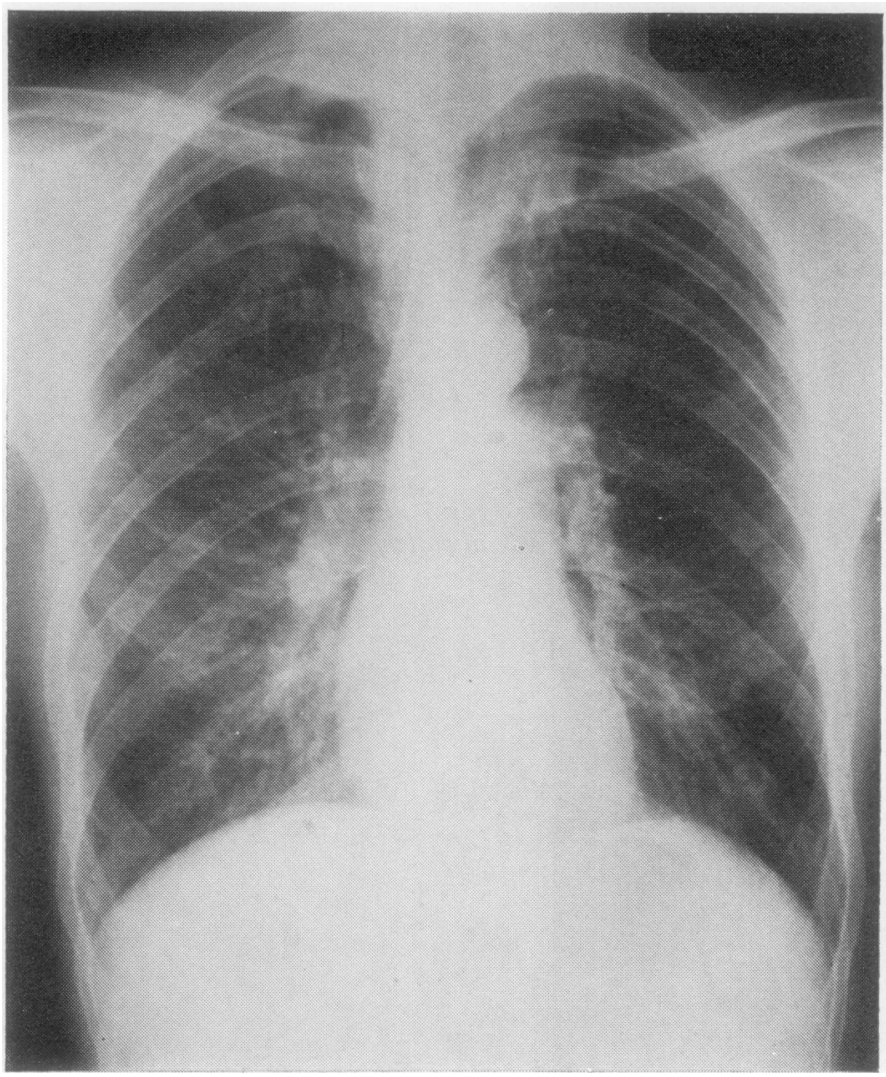

Fig 2 Postoperative PA chest radiograph in patient 7 .

Table 4 Pulmonary functions after bullectomy

\begin{tabular}{|c|c|c|c|c|c|c|c|c|}
\hline \multirow[t]{2}{*}{ Patient } & \multicolumn{3}{|c|}{ Before surgery } & \multicolumn{5}{|c|}{ After surgery } \\
\hline & \multirow{2}{*}{$\begin{array}{l}F E V_{1}(l) \\
0.32\end{array}$} & \multirow{2}{*}{$\begin{array}{l}F V C(l) \\
0.99\end{array}$} & \multirow{2}{*}{$\begin{array}{l}F E V_{1} / F V C \% \\
32\end{array}$} & \multicolumn{2}{|c|}{$\begin{array}{l}F E V_{1}\left(\% \text { change in } F E V_{1}\right) \\
(I)\end{array}$} & \multicolumn{2}{|c|}{$\begin{array}{l}F V C(\% \text { change in } F V C \\
(l)\end{array}$} & \multirow{2}{*}{$\frac{F E V_{1} / F V C \%}{38}$} \\
\hline 1 & & & & 0.69 & $(+115 \cdot 6)$ & 1.80 & $(+82)$ & \\
\hline 2 & 0.41 & 0.66 & 62 & & - & - & & \\
\hline 3 & 0.49 & 1.08 & 45 & & - & & & \\
\hline 4 & 0.54 & $i \cdot 51$ & 36 & 0.97 & $(+80)$ & $2 \cdot 59$ & $(+72)$ & 37 \\
\hline 5 & 0.65 & 1.58 & 41 & 1.73 & $(+166)$ & $3 \cdot 24$ & $(+105)$ & 53 \\
\hline 6 & 0.65 & $1 \cdot 65$ & 39 & & - & - & & \\
\hline 7 & 0.81 & 1.66 & 49 & $2 \cdot 92$ & $(+260)$ & $3 \cdot 78$ & $(+139)$ & 77 \\
\hline 8 & 0.68 & $1 \cdot 30$ & 52 & 0.92 & $(+35)$ & 1.94 & $(+49)$ & 47 \\
\hline 9 & $0 \cdot 76$ & $1 \cdot 18$ & 64 & & - & - & & \\
\hline 10 & $1 \cdot 34$ & 1.91 & 70 & & - & - & & \\
\hline 11 & 0.79 & $1 \cdot 30$ & 60 & 1.36 & $(+72)$ & 1.65 & $(+27)$ & 82 \\
\hline 12 & 1.67 & 1.89 & 88 & 3.02 & $(+80)$ & 3.91 & $(+107)$ & 77 \\
\hline 13 & $1 \cdot 20$ & $2 \cdot 20$ & 55 & & - & - & & \\
\hline 14 & 1.90 & $3 \cdot 61$ & 53 & $2 \cdot 51$ & $(+32)$ & 3.65 & $(+1)$ & 69 \\
\hline 15 & $1 \cdot 10$ & $1 \cdot 57$ & 70 & & - & & & \\
\hline 16 & 1.94 & $2 \cdot 80$ & 69 & $2 \cdot 11$ & $(+9)$ & $2 \cdot 11$ & $(-25)$ & 100 \\
\hline 17 & 1.73 & $3 \cdot 38$ & 51 & $2 \cdot 27$ & $(+31)$ & 3.89 & $(+15)$ & 58 \\
\hline 18 & $1 \cdot 78$ & $2 \cdot 67$ & 67 & 2.56 & $(+43)$ & $3 \cdot 52$ & $(+32)$ & 73 \\
\hline 19 & $1 \cdot 51$ & $2 \cdot 00$ & 76 & $1 \cdot 26$ & $(-17)$ & 1.84 & $(-8)$ & 69 \\
\hline 20 & $2 \cdot 44$ & $4 \cdot 21$ & 58 & $2 \cdot 65$ & $(+8)$ & $4 \cdot 62$ & $(+10)$ & 57 \\
\hline 21 & & - & & $1 \cdot 11$ & - & $3 \cdot 12$ & & 36 \\
\hline
\end{tabular}




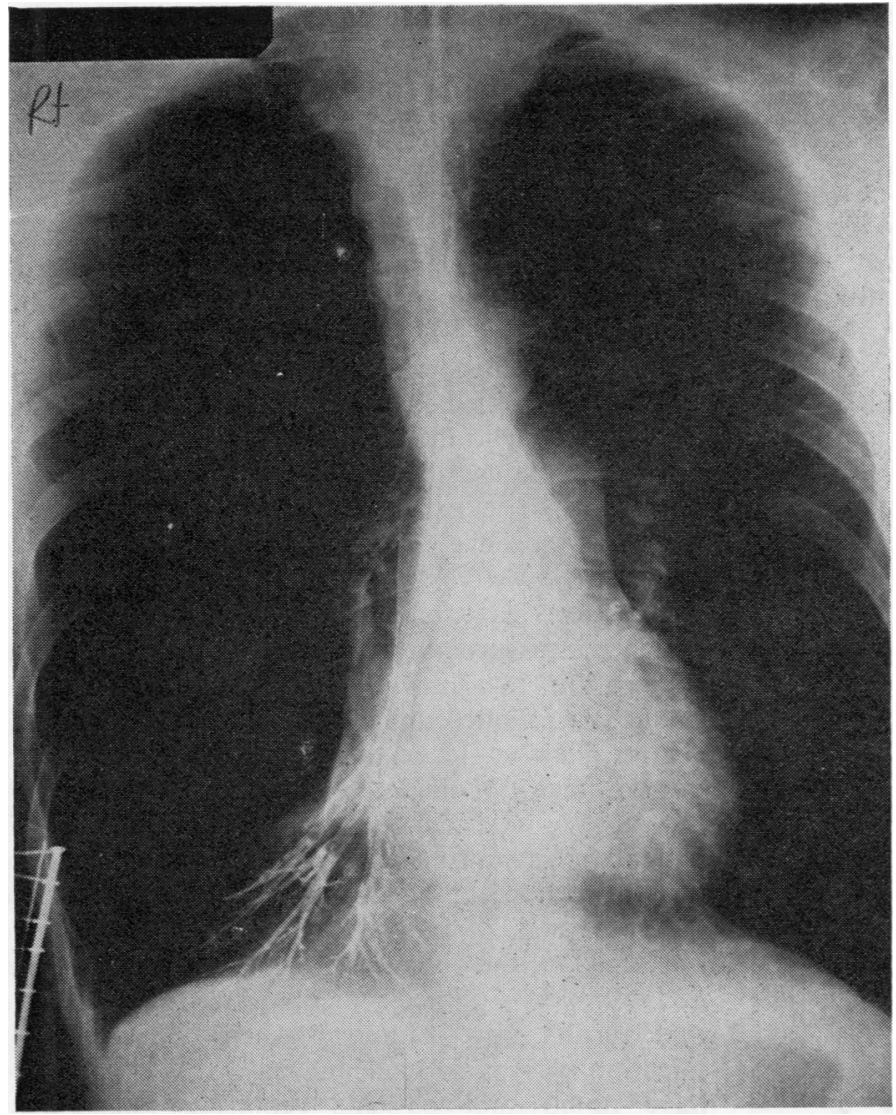

Fig 3 Preoperative bronchogram in patient 7.

from associated obstructive lung disease. Response to surgical removal of bullae could be predicted if it were possible to determine the contribution caused by the bullae as distinct from that caused by associated obstructive lung disease. Size of bullae can be assessed from PA and lateral chest radiographs and more accurately from a bronchogram. In most paiients, tests of overall lung function reflect the function of the non-bullous lung and can be used to predict the possibility of generalised emphysema by conventionally accepted criteria. ${ }^{56}$ Because the best surgical results are obtained in those patients with compressed lung that can subsequently re-expand, an important aspect of preoperative assessment is to determine the potential of lung tissue surrounding and compressed by bullae to re-expand and function. Most previous workers have used pulmonary angiograms to assess compression, but we have elected to do bronchograms in the belief that the anatomical status of the bronchi may be more informative than the vascular pattern in such patients, although we have not compared pulmonary angiograms with bronchograms to validate our choice of the latter procedure. We have been reluctant to operate on patients showing more than mild bronchiectasis on the bronchogram in the belief that such patients must have some associated pulmonary fibrosis which will prevent adequate re-expansion.

Four of 14 patients who had bronchograms showed bronchiectasis and postoperative complications occurred in all these four patients. These included empyema, pneumothorax, and failure of the compressed lung to expand adequately and fill the hemithorax. Of the 10 patients who did not show bronchiectasis on bronchography only two developed postoperative complications. These observations suggest that bronchography is useful but do not provide evidence that this investigation is any better than pulmonary angiography.

Rarely a large bulla is well ventilated and it is in such cases that the easily performed non-invasive lung scanning technique is of the greatest value. We have not found it of major value in the selection of 
the remainder of our patients for surgery. In the occasional patient in whom a bulla is well ventilated the rationale for surgery differs and here the major aim is to reduce the volume of dead space and thereby decrease the work of breathing. ${ }^{5}$

Although all our patients had a history of chronic bronchitis and evidence of generalised obstructive lung disease, most showed some improvement in their ventilatory function and their effort tolerance. Previous investigators have suggested on the basis of their own surgical results that the more severe the preoperative impairment of $\mathrm{FEV}_{1}$ the less likely the chance of marked improvement after operation. ${ }^{45}$ Of the 18 patients reported by Pride $e t$ al,$^{5}$ only seven showed an improvement in $F E_{1}$ of more than 0.3 of a litre. Our experience differs in that five out of six patients with a preoperative $\mathrm{FEV}_{1}$ of less than one litre improved by more than 0.3 of a litre postoperatively and nine of 13 patients with both pre- and postoperative measurements showed an improvement in $\mathrm{FEV}_{1}$ of more than 0.3 of a litre (fig 4). Fitzgerald et al have similarly reported striking improvements in patients with very low preoperative $\mathrm{FEV}_{1} .^{3}$

In several patients with very poor pulmonary reserve, we considered the risks of bronchography too great and surgery was undertaken after clinical

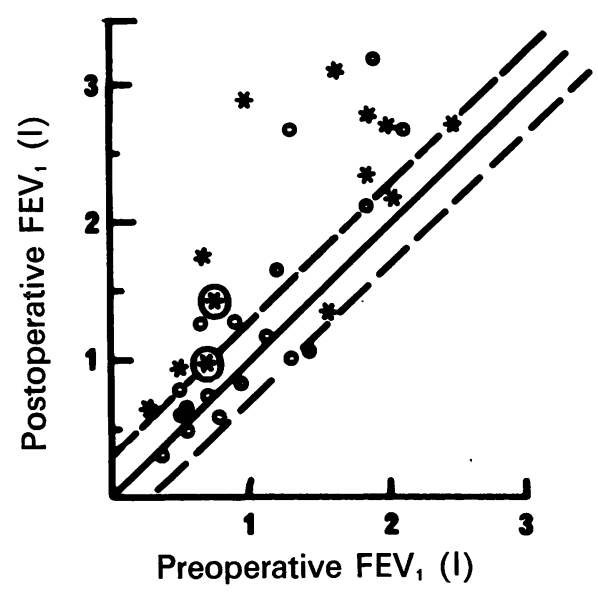

Fig 4 Pre and postoperative $F E V_{1}$ in 13 patients from the present series and 18 previously reported patients. $\ldots=$ line of identity; $-- \pm 0 \cdot 3 l ; 0=$ patients reported by Pride et al $^{\mathrm{s}}$; $*=$ present series; $\bigcirc=$ bronchiectasis on preoperative bronchogram. assessment and measurement of blood gases and spirometry. In this category were included four patients with intractable cor pulmonale and two other patients with hypercapnia before surgery. Two of these six patients died shortly after surgery, but the remaining four all showed considerable postoperative improvement.

Our mortality rate of $9.5 \%$ (two out of 21 patients) is similar to that reported by Gunstensen, ${ }^{4}$ but higher than the $2.1 \%$ mortality reported by Fitzgerald et al. ${ }^{3}$ Fitzgerald reported a $15 \%$ mortality in 140 patients collected from five British series. ${ }^{3}$ Our two patients who died postoperatively came from a group of hypercapnic patients, four with clinical cor pulmonale. The excellent result in four of these patients we believe probably justified the decision to operate.

Our experience of the need for surgery on 21 patients in a seven-year period would suggest that surgery for bullous lung disease is needed more frequently in our community than in other major centres. This could be the result of various factors but we have not made any attempts to study this aspect. We consider that surgery is justified if patients are symptomatic and there is good evidence of compression of lung tissue. Considering the degree of impairment of lung function in the patients we operated on, the risk of surgery was relatively low and even very disabled patients were improved. The best results were obtained when bullectomy or plication was performed and as in other series we have noted that patients requiring lobectomies $(16.7 \%$ in Fitzgerald's series and $15 \%$ in our series $)$ did not do as well.

\section{References}

${ }^{1}$ Boushy SF, Kohen R, Billig DM, Heiman MJ. Bullous emphysema: clinical roentgenologic and physiologic study of 49 patients. Dis Chest $1968 ; 54: 327-34$.

${ }^{2}$ Hugh-Jones P, Ritchie BC, Dollery CT. Surgical treatment of emphysema. Br Med J 1966;1:1133-8.

${ }^{3}$ Fitzgerald MX, Keelan PJ, Cugell DW, Gaensler EA. Long-term results of surgery for bullous emphysema. J Thorac Cardiovasc Surg 1974;68:566-87.

4 Gunstensen J, McCormack RJM. The surgical management of bullous emphysema. $J$ Thorac Cardiovasc Surg $1973 ; 65: 920-5$.

${ }^{5}$ Pride NB, Barter CE, Hugh-Jones P. The ventilation of bullae and the effect of their removal on thoracic gas volumes and tests of overall pulmonary function. $\mathrm{Am}$ Rev Respir Dis 1973;107:83-98.

- Burrows B, Fletcher CM, Heard BE, Jones NL, Wootliff JS. The emphysematous and bronchial types of chronic airways obstruction. Lancet 1966;1:830-5. 